\title{
Reversed-phase dispersive liquid-liquid microextraction for elemental analysis in gasoline by inductively coupled plasma optical emission spectrometry
}

\author{
Ezequiel Vidal ${ }^{\mathrm{a}}$, Anabela S. Lorenzetti ${ }^{*}$, Mónica B. Álvarez ${ }^{\mathrm{a}}$, Claudia Domini ${ }^{\mathrm{a}}$, Miguel \\ Ángel Aguirre ${ }^{\mathrm{b}}$, Lorena Vidal ${ }^{\mathrm{b}}$ and Antonio Canals ${ }^{\mathrm{b}}$ \\ ${ }^{a}$ INQUISUR, Departamento de Química, Universidad Nacional del Sur (UNS)-CONICET, Av. Alem \\ 1253, 8000 Bahía Blanca, Argentina. \\ ${ }^{b}$ Departamento de Química Analítica, Nutrición y Bromatología, Instituto Universitario de Materiales, \\ Universidad de Alicante, P.O. Box 99, 03080 Alicante, Spain. \\ *Corresponding authors: anabela.lorenzetti@gmail.com, aguirre.pastor@ua.es
}

\begin{abstract}
In this work a green and fast sample preparation method based on reversed-phase dispersive liquid-liquid microextraction (RP-DLLME) was developed for the separation and preconcentration of several elements (i.e., $\mathrm{Ag}, \mathrm{As}, \mathrm{Ba}, \mathrm{Cd}, \mathrm{Cr}, \mathrm{Cu}, \mathrm{Hg}, \mathrm{Mn}, \mathrm{Mo}, \mathrm{Ni}$, $\mathrm{Pb}, \mathrm{S}, \mathrm{Se}, \mathrm{Sn}$ and $\mathrm{V}$ ) in gasoline samples before Inductively Coupled Plasma Optical Emission Spectrometry (ICP OES) detection. The extraction procedure was carried out in a reverse mode, since a small volume of aqueous phase (i.e., acidic aqueous solution) is used to extract a relatively high volume of organic phase (i.e., gasoline sample). Unlike conventional DLLME, in the RP-DLLME the analytes were extracted from the organic phase into the aqueous phase. The experimental conditions for the microextraction procedure were: $5 \mathrm{~g}$ of amount of sample, $\mathrm{HCl} 8 \mathrm{M}$ as extractant phase, vortex as dispersion system, $115 \mu \mathrm{L}$ of extractant volume, and 2 min for extraction and 5 min centrifugation time. Under optimized extraction conditions the enrichment factor ranged between 3-53, and limits of detection ranged between 0.02 and $50 \mu \mathrm{g} \mathrm{kg}^{-1}$. The proposed analytical method was validated and successfully used to analyze three realworld samples (i.e., gasoline). All gasoline samples were spiked at $100 \mu \mathrm{g} \mathrm{kg}^{-1}$ for all analytes, except sulfur (in this case at $1000 \mu \mathrm{g} \mathrm{kg}-1$ ), obtaining recovery and RSD values within the range of $88-109 \%$ and $2-9 \%$, respectively.
\end{abstract}

\section{Introduction}

The presence of trace metals in gasoline, unless they are added purposely, is usually undesirable, as they can be responsible for the poor performance of the gasoline, leading 
to deterioration of some engine components [1]. Although some metals are natural constituents of crude oil, others can be found into the gasoline as contaminants (e.g., in the transport and storage container) [2]. Thus, gasoline chemical composition plays an important and essential role, not only for information about fuel quality but also for pollution monitoring [3].

Metallic elements in gasoline are normally present in very low concentration, therefore, it is required the employment of sensitive techniques such as X-Ray Fluorescence (XRF) [4,5], Electrothermal Atomic Absorption Spectrometry (ETAAS) [1,6], Inductively Coupled Plasma Mass Spectrometry (ICP-MS) [7,8], Flame Atomic Absorption Spectrometry (FAAS) [9], and Inductively Coupled Plasma Optical Emission Spectrometry (ICP OES)[10]. ICP OES technique is an excellent option for metal trace determination due to it allows the simultaneous determination of a great variety of elemental analytes due to its high selectivity and sensitivity [11].

Nevertheless, the aforementioned techniques are often not sufficient to achieve the required sensitivity in complex matrices, thus sample pretreatment methods must be used to reach high preconcentration factors. In recent years, Dispersive Liquid-Liquid Microextraction (DLLME) has emerged as an attractive preconcentration method, allowing the extraction and preconcentration of analytes from complex samples [12]. The DLLME technique offers many advantages such as rapid analysis time, simple setup, inexpensive equipment, high extraction efficiency and enrichment factor [13]. The conventional DLLME is carried out in a ternary system composed of an aqueous sample, extractant and dispersant solvents. Thus, the dispersant (e.g., acetonitrile) solvent dispersed the extractant solvent (e.g., chlorinated solvents) into fine droplets increasing the contact area between the sample and the extractant phase, transferring rapidly the analyte from the sample to the extractant phase $[14,15]$. After extraction and centrifugation steps, the direct analysis of the enriched organic phase into the elemental detection system is discouraged due to incompatibility of the solvent with the technique. For this reason, an additional step of dilution or back extraction is required. When the sample is immiscible with water, aqueous extractant solvent is an excellent option, appearing a new modality of DLLME called Reverse Phase Dispersive Liquid-Liquid Microextraction (RP-DLLME). In this modality, aqueous solvents are employed as extractant solvent [16]. The RP-DLLME provides the ability of introducing the extract (i.e., acidic aqueous solution) directly into the elemental detection system [17]. 
Recently, Özzeybek et al. reported the determination of cadmium traces in fish and olive oil samples [18], achieving both green and sensitive analytical methods.

The purpose of this work is to present a simple, fast, efficient, and environmentally friendly RP-DLLME procedure, using acidic aqueous solution as a valuable extractant solvent for the simultaneous separation and preconcentration of several elements (i.e., $\mathrm{Ag}, \mathrm{As}, \mathrm{Ba}, \mathrm{Cd}, \mathrm{Cr}, \mathrm{Cu}, \mathrm{Hg}, \mathrm{Mn}, \mathrm{Mo}, \mathrm{Ni}, \mathrm{Pb}, \mathrm{S}, \mathrm{Se}, \mathrm{Sn}$ and V) in gasoline samples for subsequent measurement by ICP OES.

\section{Experimental}

\subsection{Reagents and real-world samples}

Working solutions were prepared from: (i) multi-element standard Conostan S-21 (Conostan, SCP Science, Baie D'Urfé, Canada) containing $500 \mu \mathrm{g} \mathrm{g}^{-1}$ of Ag, Ba, Cd, $\mathrm{Cr}, \mathrm{Cu}, \mathrm{Mn}, \mathrm{Mo}, \mathrm{Ni}, \mathrm{Pb}, \mathrm{Sn}$, and V, and (ii) mono-element stock solution (Conostan) containing $10,000 \mu \mathrm{g} \mathrm{g}^{-1}$ of S, $500 \mu \mathrm{g} \mathrm{g}^{-1}$ of As and Se, and $100 \mu \mathrm{g} \mathrm{g}^{-1}$ of $\mathrm{Hg}$. The solvent used in the calibration standards and as a blank was kerosene (Panreac, Barcelona, Spain; boiling range $190-250{ }^{\circ} \mathrm{C}$ ). The extractant phase was prepared by an appropriate dilution of an ultra-pure $\mathrm{HCl}$ acid $\left(32 \% \mathrm{w} \mathrm{w}^{-1}\right.$, Merck Pro Analysis, Darmstadt, Germany) in distilled deionized water (18 M $\Omega . c m$ resistivity).

The applicability of the analytical method proposed was evaluated using three commercial fuel samples of 95 RON gasoline. The samples were purchased at different petrol stations close to the University of Alicante and were stored in polyethylene terephthalate (PET) containers and kept in the refrigerator until analyzed. Before performing the analysis, the samples were allowed to reach room temperature.

\subsection{Instrumentation}

All measurements were performed with an inductively coupled plasma optical emission spectrometer (model 720-ES, Agilent Technologies, Melbourne, Australia) working in axially viewed plasma mode. Table 1 shows the optimum operating conditions and emission lines evaluated in ICP OES. The RF generator power and gas flow rates (i.e., plasma, auxiliary, and nebulizing gas flow rates) were optimized achieving the maximum analyte intensities using a standard solution containing $1 \mu \mathrm{g} \mathrm{g}^{-1}$ of all analytes in kerosene (Panreac), except sulfur in which concentration was $10 \mu \mathrm{g} \mathrm{g}^{-1}$. 


\subsection{RP-DLLME optimization}

RP-DLLME optimization was performed using a multivariate approach consisting of a Plackett-Burman factorial design in order to identify the significant factors [19]. In these studies, the experiments were randomly performed in order to nullify the effect of extraneous or nuisance factors. After the screening study, only one significant factor was found and univariate optimization was carried out by monitoring the effect of this variable (i.e., extractant volume) on the signal intensity values. On these investigations, a standard solution containing $100 \mu \mathrm{g} \mathrm{kg}^{-1}$ of all analytes was used, except sulfur. In this case a concentration of $2000 \mu \mathrm{g} \mathrm{kg}^{-1}$ was employed.

\subsection{RP-DLLME procedure}

Under optimized conditions, $5 \mathrm{~g}$ of calibration standards or $95 \mathrm{RON}$ gasoline samples were placed in a glass centrifuge tube. Then, $115 \mu \mathrm{L}$ of aqueous $8 \mathrm{M} \mathrm{HCl}$ solution were added and the mixture was shaken for 2 min using vortex agitation. Then, phases were separated by centrifugation for $5 \mathrm{~min}$ at $4000 \mathrm{rpm}$. The upper organic phase was carefully removed with a glass pipette and the remaining acidic aqueous phase (i.e., 100 $\mu \mathrm{L}$ ) was retrieved with a syringe for final analysis by ICP OES. Figure 1 shows a scheme of the overall procedure.

\subsection{Data processing}

A multivariate optimization strategy was carried out to determine optimum conditions for RP-DLLME. The statistical software NEMRODW ${ }^{\circledR}$ ("New Efficient Methodology for Research using Optimal Design") from LPRAI (Marseille, France) was used to build the experimental design matrix and evaluate the results. In this study, the individual emission intensities were the response functions for optimization.

\section{Results and discussion}

\subsection{RP-DLLME optimization}

Numerous factors can affect extraction yield in the RP-DLLME procedure. Therefore, optimization through a multivariate approach was carried out.

\subsubsection{Screening study}

A Plackett-Burman design was used to construct the matrix of experiments, including six factors in twelve runs. The factors investigated at two levels in this work were: 
amount of sample, type of extractant phase, extractant volume, dispersion system, and extraction and centrifugation time. Table 2 shows the considered experimental factors and levels in the Plackett-Burman design.

Pareto charts of this screening study are shown in Figure 2. The relative influence of the corresponding factor, and those bars that exceed reference vertical lines (dashed lines) can be considered significant with $95 \%$ probability. In addition, rightward bars indicate a positive effect in the response when increasing from a lower to high level, while leftward bars indicate a negative effect upon the response when passing from a lower to upper level of the corresponding factor. Figure 2 shows that all the Pareto charts present a similar response for almost all of the factors, varying degrees of significance depending on the analyte. The exceptions are the extraction and centrifugation time which present different effects (i.e., positive or negative) depending on the evaluated analyte. However, the majority of the analytes show a positive effect in the extraction and centrifugation time. Besides, these variables were non-significant. Thus, they were fixed at $2 \min$ (the extraction time) and $5 \mathrm{~min}$ (centrifugation time).

Interpretation of the graphic study presented in Figure 2 leads to conclude that only three factors (i.e., extractant phase type, extractant volume and dispersion system) are statistically significant in the emission lines evaluated. Amount of sample was nonsignificant with negative effect, and therefore, this factor was fixed at its low level (i.e., $5 \mathrm{~g})$. The type of extractant phase and dispersion system had both positive effects, and they were chosen at their high level (i.e., $8 \mathrm{M} \mathrm{HCl}$ as extractant phase and vortex as dispersion system). According to a previous publication, this acid plays a significant role in the extraction step, in both organic and inorganic analytes [20,21]. On the other hand, some authors suggest that using the vortex in a mixture of two immiscible liquids directly provides the mechanical energy needed to break up the drop. However, it should be noted there are three different steps that are generated during emulsion formation: deforming, breaking up and rejoining the droplets [22,23]. In accordance with the result of the screening study, the extractant volume was the only factor to be optimized and it was thoroughly studied varying the extractant volume from 115 to 285 $\mu \mathrm{L}$, with the other factors at the corresponding fixed level. 


\subsubsection{Optimization study of extractant volume}

Figure 3 shows the resulting normalized signal of the average of all emission lines evaluated. The signal of each element was normalized with respect to the maximum signal for each one. In Figure 3, the signal intensity decreases by increasing the extractant volume from 115 to $285 \mu \mathrm{L}$. It is well known that increasing the extractant volume leads to an increase in metal extraction. In contrast, an excessive extract volume could lead to a dilution effect, thus decreasing the preconcentration factor. It is easy to predict that the optimum extract volume is below $115 \mu \mathrm{L}$. However, it was impossible to perform the analysis using a lower volume than $115 \mu \mathrm{L}$, since it was the minimum volume required to measure all emission lines analyzed.

Summarizing, optimal RP-DLLME conditions were: $5 \mathrm{~g}$ of sample weight, $\mathrm{HCl} 8 \mathrm{M}$ as extractant phase, vortex as dispersion system, $115 \mu \mathrm{L}$ of extractant volume, and $2 \mathrm{~min}$ for extraction and 5 min centrifugation time.

\subsection{Validation of the method}

The main analytical figures of merit of the proposed method are summarized in Table 3. The working range showed good linearity with correlation coefficients (r) from 0.9752 to 0.9997 , being the majority of values higher than 0.995 . The repeatability of the method was evaluated by analyzing five spiked solutions at 10 and $100 \mu \mathrm{g} \mathrm{kg}^{-1}$, except sulfur where the spiked concentrations were 500 and $2000 \mu \mathrm{g} \mathrm{kg}^{-1}$. The obtained RSD \% values varied between 3 and 12\% (Table 3). Enrichment factors (EFs) were calculated as the ratio of the sensitivity obtained with and without RP-DLLME. Arsenic gave the highest extraction performance of the studied analytes, with an EF value of 53, whereas barium showed the lowest extraction performance (i.e., EF=3). LOD values were calculated following the $3 \sigma_{\text {blank }}$ criteria, being $\sigma_{\text {blank }}$ the standard deviation of 10 blank measurements, in accordance with Eurachem guidelines [24]. Overall emission lines evaluated, barium offered the most sensitive results in the analysis, obtaining a sensitivity of $4000 \pm 300 \mathrm{cps} \mathrm{kg} \mathrm{gg}^{-1}$ and a LOD of $0.02 \mu \mathrm{g} \mathrm{kg}^{-1}$. Conversely, the highest LOD value was obtained for sulfur (i.e., $50 \mu \mathrm{g} \mathrm{kg}^{-1}$ ).

\subsection{Analysis of real samples}

The original concentrations of the analytes in the three commercial samples analyzed by external calibration were below the LOD, except for sulfur in the three samples and 
selenium in samples 1 and 2 . Hence, in order to assess the applicability of the proposed analytical method, spiked commercial fuel samples were analyzed. Consequently, the three gasoline samples were spiked at $100 \mu \mathrm{g} \mathrm{kg}^{-1}$ levels of all analytes, except sulfur. In this case, all samples were spiked with $1000 \mu \mathrm{g} \mathrm{kg}^{-1}$ (Table 4). According to these results, there were no significant differences between the concentrations added and those found in all gasoline samples, obtaining relative recoveries ranged between 88 and $109 \%$. Therefore, non-significant matrix effects were found with the proposed methodology.

\subsection{Comparison with other methods}

In order to compare the developed method with previously reported ones, various publications were found in which the same analytes were determined in real fuel samples. The techniques used in the studies consulted differ in either the detection technique or the microextraction technique, or both. In Table 5 it can be seen that the number of analytes quantified simultaneously is the highest for the developed method. Besides, the time used for the microextraction of the analytes is one of the lowest used thanks to the speed obtained by the RP-DLLME procedure. It should be noted that acidic water solution is a solvent significantly cheaper and greener than other organic solvents and sorbents employed in the bibliography. Even though these publications determinate heavy metals in gasoline samples, to our knowledge, the use of water solution as an extract solvent has not been reported in elemental analysis in gasoline samples. In addition, the analytical method proposed meets with the majority of the 12 principles of Green Analytical Chemistry, especially those related with the reduction of reagents, the use of non-hazardous reagents obtained from renewable sources, the use of miniaturized methods, the safety of the operator, multi-analyte methods, low sample consumption and analytical waste.

\section{Conclusions}

A RP-DLLME has been investigated for the elemental analysis in commercial fuel samples by ICP OES. The results obtained in this work showed that the RP-DLLME is a successful analytical method for the separation and preconcentration of several analytes from gasoline samples, improving their figures of merits (i.e., a high enhancement factor is obtained) by ICP OES. The application of this microextraction 
procedure avoided a laborious and time-consuming digestion procedure that is a mandatory step before the injection of high carbon content samples, resulting in a procedure with very low LOQ. The method was applied to the elemental analysis of three commercial gasoline samples with the additional advantages of using an aqueous extractant solution. The proposed method was carried out using only $115 \mu \mathrm{L}$ of aqueous $8 \mathrm{M} \mathrm{HCl}$ as extractant, reducing drastically the reagent consumption and also the generation of lab residues. In addition, the analytes were extracted to an aqueous phase completely compatible with ICP OES instrumentation, avoiding possible interferences from the organic sample matrix. The results clearly showed that this analytical method is promising and satisfactorily accurate to be used for elemental analysis of gasoline samples by ICP OES.

\section{Acknowledgements}

The authors would like to thank the Regional Government of Valencia (Spain) (PROMETEO/2018/087) for the financial support, Agilent Technologies Inc. for the loan of the ICP OES spectrometer, and Ingeniatrics for the OneNeb ${ }^{\circledR}$ provided. Financial support from Universidad Nacional del Sur is gratefully acknowledged. A.S. Lorenzetti E. Vidal and C.E. Domini wish to thank Consejo Nacional de Investigaciones Científicas y Técnicas for the financial support received. The authors extend their appreciation to Ministry of Science, Innovation and Universities for granting the Spanish Network of Excellence in Sample Preparation (RED2018-102522-T). This article is based upon work from the Sample Preparation Study Group and Network, supported by the Division of Analytical Chemistry of the European Chemical Society. 
Table 1. Operating conditions for ICP OES.

\begin{tabular}{ll}
\hline Parameters & Value \\
\hline Nebulizer type & OneNeb ${ }^{\circledR}$ \\
Spray chamber & Cyclonic \\
RF generator power & $1200(\mathrm{~W})$ \\
Plasma gas flow rate $\left(\mathrm{L} \mathrm{min}^{-1}\right)$ & 15 \\
Auxiliary gas flow rate $\left(\mathrm{L} \mathrm{min}^{-1}\right)$ & 1.5 \\
Nebulizing gas flow rate $\left(\mathrm{L} \mathrm{min}^{-1}\right)$ & 0.75 \\
Sample liquid flow $\left(\mu \mathrm{L} \mathrm{min}{ }^{-1}\right)$ & 100 \\
Replicates & 3 \\
Viewing mode & $\mathrm{Axial}$ \\
Emission lines $(\mathrm{nm})$ & $\mathrm{Ag}(328.068), \mathrm{As} \mathrm{(193.696),} \mathrm{Ba}$ \\
& $(455.403), \mathrm{Cd}(214.439), \mathrm{Cr}(267.716)$, \\
& $\mathrm{Cu}(324.754), \mathrm{Hg}(253.652), \mathrm{Mn}$ \\
$(257.610), \mathrm{Mo}(202.032), \mathrm{Ni}(216.555)$, \\
$\mathrm{Pb}(220.353), \mathrm{S}(181.972), \mathrm{Se}(196.026)$, \\
$\mathrm{Sn}(283.998)$ and V (311.837).
\end{tabular}


Table 2. Experimental factors and levels of the Plackett-Burman design.

\begin{tabular}{lll}
\hline Experimental factor & Low level (-1) & High level (+1) \\
\hline Amount of sample $(\mathrm{g})$ & 5 & 7 \\
Type of extractant phase & $\mathrm{HNO}_{3}(8 \mathrm{M})$ & $\mathrm{HCl}(8 \mathrm{M})$ \\
Extractant volume $(\mu \mathrm{L})$ & 150 & 250 \\
Dispersion system & Ultrasound & Vortex \\
Extraction time (min) & 1 & 2 \\
Centrifugation time (min) & 3 & 5 \\
\hline
\end{tabular}


Table 3. Analytical figures of merit of the proposed method (RP-DLLME/ICP OES).

\begin{tabular}{|c|c|c|c|c|c|c|c|c|}
\hline \multirow[b]{2}{*}{ Analyte } & \multirow[b]{2}{*}{$\begin{array}{l}\text { Working } \\
\text { range } \\
\left(\mu \mathrm{g} \mathrm{kg}^{-1}\right)\end{array}$} & \multirow[b]{2}{*}{$\mathrm{r}^{\mathrm{a}}$} & \multirow[b]{2}{*}{$\begin{array}{l}\text { Sensitivity } \\
\left(\operatorname{cps~kg~} \mu \mathrm{g}^{-1}\right)^{\mathrm{b}}\end{array}$} & \multicolumn{2}{|c|}{$\operatorname{RSD}(\%)^{\mathrm{c}}$} & \multirow[b]{2}{*}{$\underset{\left(\mu \mathrm{g} \mathrm{kg}^{-1}\right)}{\mathrm{LOD}}$} & \multirow[b]{2}{*}{$\begin{array}{c}\mathrm{LOQ} \\
\left(\mu \mathrm{g} \mathrm{kg}^{-1}\right)\end{array}$} & \multirow[b]{2}{*}{$\mathrm{EF}^{\mathrm{d}}$} \\
\hline & & & & $\begin{array}{c}10 \\
\left(\mu \mathrm{g} \mathrm{kg}^{-1}\right)\end{array}$ & $\begin{array}{c}100 \\
\left(\mu \mathrm{gg}^{-1}\right)\end{array}$ & & & \\
\hline $\mathrm{Ag}$ & $10-150$ & $\begin{array}{l}0.9967 \\
\text { (4) }\end{array}$ & $232 \pm 6$ & 11 & 8 & 1.5 & 5 & 9 \\
\hline As & $50-200$ & $\begin{array}{l}0.9752 \\
\quad(4)\end{array}$ & $10.5 \pm 0.2$ & - & 7 & 6 & 20 & 53 \\
\hline $\mathrm{Ba}$ & $0.10-150$ & $\begin{array}{l}0.9985 \\
\quad(6)\end{array}$ & $4000 \pm 300$ & 4 & 7 & 0.02 & 0.05 & 3 \\
\hline $\mathrm{Cd}$ & $1.0-150$ & $\begin{array}{l}0.9987 \\
(5)\end{array}$ & $179 \pm 7$ & 9 & 8 & 0.15 & 0.5 & 14 \\
\hline $\mathrm{Cr}$ & $1.0-150$ & $\begin{array}{l}0.9988 \\
(5)\end{array}$ & $176 \pm 5$ & 11 & 7 & 0.3 & 1.0 & 7 \\
\hline $\mathrm{Cu}$ & $1.0-150$ & $\begin{array}{l}0.9955 \\
(5)\end{array}$ & $275 \pm 13$ & 13 & 6 & 0.12 & 0.4 & 9 \\
\hline $\mathrm{Hg}$ & $10-150$ & $\begin{array}{l}0.9997 \\
(4)\end{array}$ & $89.9 \pm 1.9$ & 9 & 8 & 0.9 & 3 & 24 \\
\hline $\mathrm{Mn}$ & $0.10-200$ & $\begin{array}{l}0.9977 \\
(6)\end{array}$ & $1340 \pm 70$ & 6 & 10 & 0.03 & 0.10 & 13 \\
\hline Mo & $10-150$ & $\begin{array}{l}0.9959 \\
\quad(4)\end{array}$ & $70 \pm 3$ & 12 & 11 & 1.2 & 4 & 20 \\
\hline $\mathrm{Ni}$ & $10-150$ & $\begin{array}{l}0.9945 \\
\quad(4)\end{array}$ & $55 \pm 4$ & 11 & 8 & 1.2 & 4 & 17 \\
\hline $\mathrm{Pb}$ & $10-150$ & $\begin{array}{l}0.9964 \\
(4)\end{array}$ & $18.78 \pm 0.05$ & 11 & 5 & 3 & 9 & 15 \\
\hline $\mathrm{S}$ & $500-2000$ & $\begin{array}{l}0.9832 \\
\quad(4)\end{array}$ & $3.22 \pm 0.09$ & $12 *$ & $3 *$ & 50 & 150 & 5 \\
\hline $\mathrm{Se}$ & $50-200$ & $\begin{array}{l}0.9975 \\
(4)\end{array}$ & $2.2 \pm 0.5$ & - & 10 & 12 & 40 & 5 \\
\hline $\mathrm{Sn}$ & $10-150$ & $\begin{array}{l}0.9996 \\
(4)\end{array}$ & $20.4 \pm 0.8$ & 12 & 7 & 3 & 10 & 8 \\
\hline V & $1.0-150$ & $\begin{array}{c}0.9981 \\
(5) \\
\end{array}$ & $640 \pm 70$ & 10 & 11 & 0.09 & 0.3 & 25 \\
\hline
\end{tabular}

${ }^{a}$ Correlation coefficient (r): number of calibration standards in parentheses.

${ }^{\mathrm{b}}$ Slope \pm standard deviation.

${ }^{\mathrm{c}}$ Relative standard deviation (RSD): mean value for 5 replicate analyses of 10 and 100 $\mu \mathrm{g} \mathrm{kg}{ }^{-1}$ spiked solution. ${ }^{*}$ In case of sulfur the spiked concentrations were 500 and 2000 $\mu \mathrm{g} \mathrm{kg}{ }^{-1}$.

${ }^{\mathrm{d}}$ Enrichment factor (EF): calculated as the ratio of the sensitivity obtained with and without RP-DLLME. 
Table 4. Analytical results obtained in the analysis of three spiked gasoline samples. The concentration and recovery values are expressed as the mean \pm standard deviation of the three replicates.

\begin{tabular}{|c|c|c|c|c|c|c|c|}
\hline \multirow[b]{2}{*}{ Analyte } & \multirow[b]{2}{*}{$\begin{array}{c}\text { Spike } \\
\left(\mu \mathrm{g} \mathrm{kg}^{-1}\right)\end{array}$} & \multicolumn{2}{|c|}{ Sample 1} & \multicolumn{2}{|c|}{ Sample 2} & \multicolumn{2}{|c|}{ Sample 3} \\
\hline & & $\begin{array}{l}\text { Concentration } \\
\left(\mu \mathrm{g} \mathrm{kg}^{-1}\right)\end{array}$ & R (\%) & $\begin{array}{l}\text { Concentration } \\
\left(\mu \mathrm{g} \mathrm{kg}^{-1}\right)\end{array}$ & R (\%) & $\begin{array}{l}\text { Concentration } \\
\left(\mu \mathrm{g} \mathrm{kg}^{-1}\right)\end{array}$ & $\mathrm{R}(\%)$ \\
\hline \multirow[t]{2}{*}{$\mathrm{Ag}$} & - & $<\mathrm{LOQ}$ & - & $<\mathrm{LOQ}$ & - & $<$ LOQ & - \\
\hline & 100 & $101 \pm 5$ & $101 \pm 5$ & $91 \pm 6$ & $91 \pm 6$ & $105 \pm 5$ & $105 \pm 5$ \\
\hline \multirow[t]{2}{*}{ As } & - & $<\mathrm{LOQ}$ & - & $<\mathrm{LOQ}$ & - & $<$ LOQ & - \\
\hline & 100 & $93 \pm 4$ & $93 \pm 4$ & $95 \pm 5$ & $95 \pm 5$ & $93 \pm 4$ & $93 \pm 4$ \\
\hline \multirow[t]{2}{*}{$\mathrm{Ba}$} & - & $<\mathrm{LOQ}$ & - & $<$ LOQ & - & $<$ LOQ & - \\
\hline & 100 & $102 \pm 3$ & $102 \pm 3$ & $91 \pm 4$ & $91 \pm 4$ & $105 \pm 4$ & $105 \pm 4$ \\
\hline \multirow[t]{2}{*}{$\mathrm{Cd}$} & - & $<$ LOQ & - & $<$ LOQ & - & $<$ LOQ & - \\
\hline & 100 & $92 \pm 6$ & $92 \pm 6$ & $103 \pm 3$ & $103 \pm 3$ & $106 \pm 7$ & $106 \pm 7$ \\
\hline \multirow[t]{2}{*}{$\mathrm{Cr}$} & - & $<\mathrm{LOQ}$ & - & $<\mathrm{LOQ}$ & - & $<$ LOQ & - \\
\hline & 100 & $90 \pm 4$ & $90 \pm 4$ & $94 \pm 4$ & $94 \pm 4$ & $93 \pm 5$ & $93 \pm 5$ \\
\hline \multirow[t]{2}{*}{$\mathrm{Cu}$} & - & $<\mathrm{LOQ}$ & - & $<\mathrm{LOQ}$ & - & $<$ LOQ & - \\
\hline & 100 & $106 \pm 5$ & $106 \pm 5$ & $105 \pm 3$ & $105 \pm 3$ & $108 \pm 3$ & $108 \pm 3$ \\
\hline \multirow[t]{2}{*}{$\mathrm{Hg}$} & - & $<\mathrm{LOQ}$ & - & $<\mathrm{LOQ}$ & - & $<$ LOQ & - \\
\hline & 100 & $90 \pm 7$ & $90 \pm 7$ & $92 \pm 4$ & $92 \pm 4$ & $107 \pm 4$ & $107 \pm 4$ \\
\hline \multirow[t]{2}{*}{$\mathrm{Mn}$} & - & $<\mathrm{LOQ}$ & - & $<\mathrm{LOQ}$ & - & $<$ LOQ & - \\
\hline & 100 & $102 \pm 5$ & $102 \pm 5$ & $93 \pm 4$ & $93 \pm 4$ & $105 \pm 4$ & $105 \pm 4$ \\
\hline \multirow[t]{2}{*}{ Mo } & - & $<\mathrm{LOQ}$ & - & $<\mathrm{LOQ}$ & - & $<$ LOQ & - \\
\hline & 100 & $98 \pm 7$ & $98 \pm 7$ & $94 \pm 3$ & $94 \pm 3$ & $96 \pm 5$ & $96 \pm 5$ \\
\hline \multirow[t]{2}{*}{$\mathrm{Ni}$} & - & $<\mathrm{LOQ}$ & - & $<\mathrm{LOQ}$ & - & $<$ LOQ & - \\
\hline & 100 & $99 \pm 6$ & $99 \pm 6$ & $93 \pm 4$ & $93 \pm 4$ & $91 \pm 7$ & $91 \pm 7$ \\
\hline \multirow[t]{2}{*}{$\mathrm{Pb}$} & - & $<$ LOQ & - & $<$ LOQ & - & $<$ LOQ & - \\
\hline & 100 & $88 \pm 6$ & $88 \pm 6$ & $101 \pm 3$ & $101 \pm 3$ & $99 \pm 5$ & $99 \pm 5$ \\
\hline \multirow[t]{2}{*}{ S } & - & $1978 \pm 81$ & - & $1674 \pm 113$ & - & $1354 \pm 138$ & - \\
\hline & 1000 & $2936 \pm 147$ & $96 \pm 5$ & $2604 \pm 87$ & $93 \pm 6$ & $2394 \pm 79$ & $104 \pm 7$ \\
\hline \multirow[t]{2}{*}{$\mathrm{Se}$} & - & $97 \pm 6$ & - & $51 \pm 4$ & - & $<$ LOQ & - \\
\hline & 100 & $199 \pm 12$ & $102 \pm 6$ & $160 \pm 8$ & $109 \pm 4$ & $103 \pm 8$ & $103 \pm 8$ \\
\hline \multirow[t]{2}{*}{$\mathrm{Sn}$} & - & $<\mathrm{LOQ}$ & - & $<\mathrm{LOQ}$ & - & $<$ LOQ & - \\
\hline & 100 & $98 \pm 2$ & $98 \pm 2$ & $107 \pm 9$ & $107 \pm 9$ & $106 \pm 4$ & $106 \pm 4$ \\
\hline \multirow[t]{2}{*}{$\mathrm{V}$} & - & $<\mathrm{LOQ}$ & - & $<\mathrm{LOQ}$ & - & $<$ LOQ & - \\
\hline & 100 & $94 \pm 4$ & $94 \pm 4$ & $98 \pm 5$ & $98 \pm 5$ & $107 \pm 5$ & $107 \pm 5$ \\
\hline
\end{tabular}


Table 5. Comparison between different methods for elemental analysis in fuel samples. ${ }^{\text {a }}$

\begin{tabular}{|c|c|c|c|c|c|c|c|}
\hline $\begin{array}{l}\text { Detection } \\
\text { Technique }\end{array}$ & $\begin{array}{c}\text { Sample } \\
\text { preparation }\end{array}$ & Sample & Analyte & $\begin{array}{l}\text { Extraction } \\
\text { time (min) }\end{array}$ & Enrichment Factor & $\begin{array}{c}\text { LOQ } \\
\left(\mu \mathrm{g} \mathrm{L}^{-1}\right)\end{array}$ & $\begin{array}{l}\text { Referen } \\
\text { ce }\end{array}$ \\
\hline EDXRF & MSPME & $\begin{array}{l}\text { Ethanol } \\
\text { Fuel }\end{array}$ & $\begin{array}{c}\mathrm{Cu}, \mathrm{Cd}, \\
\mathrm{Pb}, \mathrm{Cr}, \mathrm{V}, \\
\mathrm{Mn}\end{array}$ & 11 & NI & $\begin{array}{l}36(\mathrm{Cu}), 39(\mathrm{Cd}), \\
48(\mathrm{~Pb}), 36(\mathrm{Cr}), \\
27(\mathrm{~V}), 33(\mathrm{Mn})\end{array}$ & [4] \\
\hline EDXRF & $\begin{array}{c}\text { RP- } \\
\text { VALLME }\end{array}$ & Diesel oil & $\begin{array}{l}\mathrm{Cu}, \mathrm{Mn}, \\
\mathrm{Ni}, \mathrm{Pb}\end{array}$ & $<1$ & $\begin{array}{c}34(\mathrm{Cu}), 62(\mathrm{Mn}) \\
59(\mathrm{Ni}), 64(\mathrm{~Pb})\end{array}$ & $\begin{array}{c}47(\mathrm{Cu}), 26(\mathrm{Mn}) \\
34(\mathrm{Ni}), 23(\mathrm{~Pb})\end{array}$ & [5] \\
\hline ETAAS & $\begin{array}{c}\text { MIL } \\
\text { DLLME }\end{array}$ & $\begin{array}{l}\text { Gasoline } \\
\text { and diesel }\end{array}$ & $\mathrm{Cd}$ & 2 & 220 & $0.28^{*}$ & {$[1]$} \\
\hline ETAAS & $\begin{array}{l}\text { Emulsion } \\
\text { breaking and } \\
\text { DLLME }\end{array}$ & $\begin{array}{c}\text { Biodiesel } \\
\text { and oil }\end{array}$ & $\mathrm{Cu}, \mathrm{Pb}$ & 30 & $18(\mathrm{Cu}), 2.5(\mathrm{~Pb})$ & $\begin{array}{c}0.76(\mathrm{Cu}) \\
0.81(\mathrm{~Pb})\end{array}$ & {$[6]$} \\
\hline ICP-MS & $\begin{array}{l}\text { Emulsion } \\
\text { breaking }\end{array}$ & Gasoline & $\begin{array}{l}\mathrm{Cd}, \mathrm{Mn} \\
\mathrm{Pb}, \mathrm{Sb}\end{array}$ & $<1$ & NI & $\begin{array}{c}0.1(\mathrm{Cd}), 2(\mathrm{Mn}) \\
0.2(\mathrm{~Pb}) \\
0.07(\mathrm{Sb})\end{array}$ & {$[7]$} \\
\hline ICP-MS & HF-SPME & $\begin{array}{l}\text { Gasoline } \\
\text { and diesel }\end{array}$ & $\begin{array}{l}\mathrm{Cd}, \mathrm{Cu}, \\
\mathrm{Fe}, \mathrm{Pb}, \mathrm{Zn}\end{array}$ & 40 & NI & $\begin{array}{c}0.4(\mathrm{Cd}), 0.3 \\
(\mathrm{Cu}), 0.5(\mathrm{Fe}), 0.9 \\
(\mathrm{~Pb}), 0.3(\mathrm{Zn})\end{array}$ & [8] \\
\hline FAAS & $\begin{array}{l}\text { Emulsion } \\
\text { breaking }\end{array}$ & Gasoline & $\mathrm{Cu}, \mathrm{Fe}, \mathrm{Pb}$ & 10 & $\begin{array}{c}2.4(\mathrm{Cu}), 2.5(\mathrm{Fe}) \\
2.0(\mathrm{~Pb})\end{array}$ & $\begin{array}{c}11(\mathrm{Cu}), 77(\mathrm{Fe}) \\
48(\mathrm{~Pb})\end{array}$ & [9] \\
\hline ICP OES & HF-LPME & $\begin{array}{l}\text { Gasoline } \\
\text { and diesel }\end{array}$ & $\begin{array}{c}\text { Ag, Al, } \\
\text { As, Mn, Ti }\end{array}$ & 55 & $\begin{array}{c}150(\mathrm{Ag}), 291(\mathrm{Al}) \\
112(\mathrm{As}), 405(\mathrm{Mn}) \\
367(\mathrm{Ti})\end{array}$ & $\begin{array}{c}0.27(\mathrm{Ag}), 0.18 \\
(\mathrm{Al}), 0.29(\mathrm{As}), \\
0.15(\mathrm{Mn}), 0.17 \\
(\mathrm{Ti})\end{array}$ & {$[10]$} \\
\hline ICP OES & RP-DLLME & Gasoline & $\begin{array}{l}\mathrm{Ag}, \mathrm{As}, \\
\mathrm{Ba}, \mathrm{Cd}, \\
\mathrm{Cr}, \mathrm{Cu}, \\
\mathrm{Hg}, \mathrm{Mn}, \\
\mathrm{Mo}, \mathrm{Ni}, \\
\mathrm{Pb}, \mathrm{S}, \mathrm{Se}, \\
\mathrm{Sn} \text { and } \mathrm{V} .\end{array}$ & 2 & $\begin{array}{c}9(\mathrm{Ag}), 53(\mathrm{As}), \\
3(\mathrm{Ba}), 14(\mathrm{Cd}), \\
7(\mathrm{Cr}), 9(\mathrm{Cu}), \\
24(\mathrm{Hg}), 13(\mathrm{Mn}), \\
20(\mathrm{Mo}), 17(\mathrm{Ni}), \\
15(\mathrm{~Pb}), 5(\mathrm{~S}), 5(\mathrm{Se}), \\
8(\mathrm{Sn}), 25(\mathrm{~V})\end{array}$ & $\begin{array}{c}5(\mathrm{Ag}), 20(\mathrm{As}) \\
0.05(\mathrm{Ba}) \\
0.5(\mathrm{Cd}), 1.0(\mathrm{Cr}) \\
0.4(\mathrm{Cu}), 3(\mathrm{Hg}) \\
0.10(\mathrm{Mn}) \\
4(\mathrm{Mo}), 4(\mathrm{Ni}) \\
9(\mathrm{~Pb}), 150(\mathrm{~S}) \\
40(\mathrm{Se}), 10(\mathrm{Sn}) \\
0.3(\mathrm{~V})^{*}\end{array}$ & $\begin{array}{l}\text { This } \\
\text { work }\end{array}$ \\
\hline
\end{tabular}

${ }^{a}$ ET, extraction time; NI, not indicated; MIL DLLME, magnetic ionic liquid dispersive liquidliquid microextraction; EDXRF, energy dispersive X-ray fluorescence spectrometry; MSPME, magnetic solid phase microextraction; HF-SPME, hollow fiber solid phase microextraction; HFLPME, hollow fiber-liquid phase microextraction; RP-VALLME, reversed-phase vortexassisted liquid-liquid microextraction.

*LOQ values expressed in $\mu \mathrm{g} \mathrm{kg}{ }^{-1}$. 


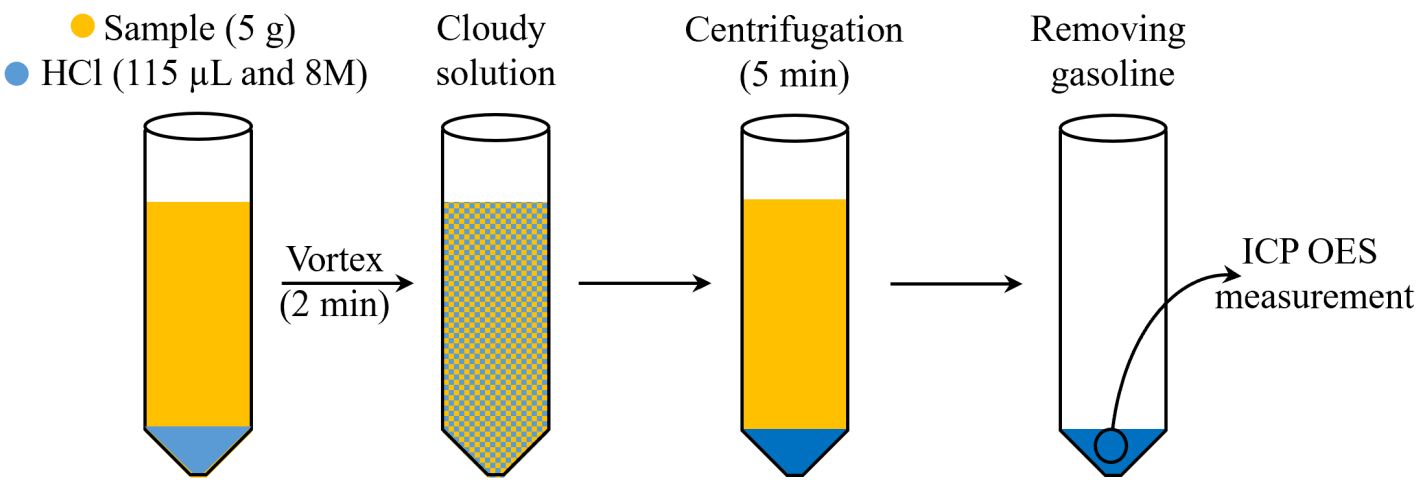

Figure 1. Scheme of the analytical procedure. 

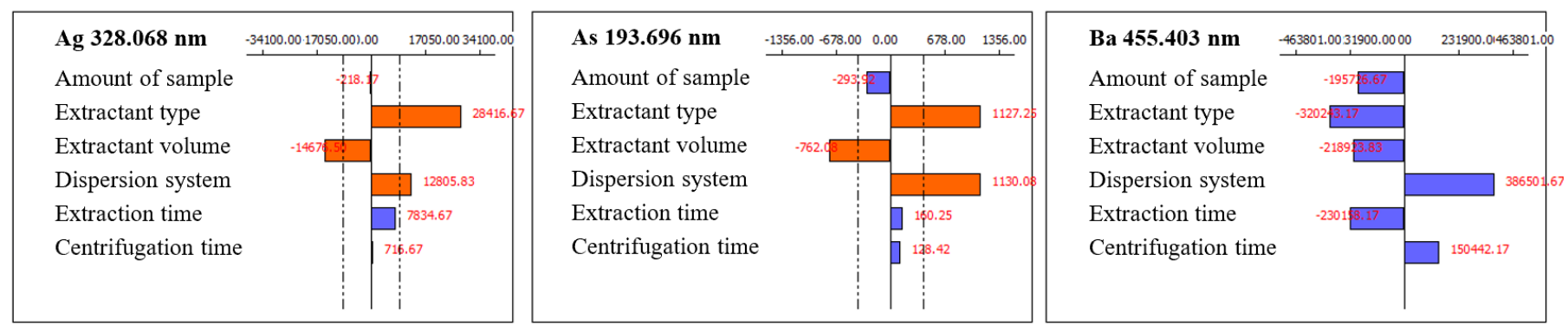

\begin{tabular}{|c|c|c|}
\hline Cd $214.439 \mathrm{~nm}$ & $-21154.00 \cdot 10577.001 .00$ & 10577.0021154 .00 \\
\hline Amount of sample & $-82 \frac{p}{p}$ & \\
\hline Extractant type & & $50 \dot{2} 2.58$ \\
\hline Extractant volume & -79 d̦o. & \\
\hline Dispersion system & & 17629. \\
\hline Extraction time & -1618 年 & : \\
\hline Centrifugation time & $-551 . d$ & i \\
\hline & $i$ & $\vdots$ \\
\hline
\end{tabular}
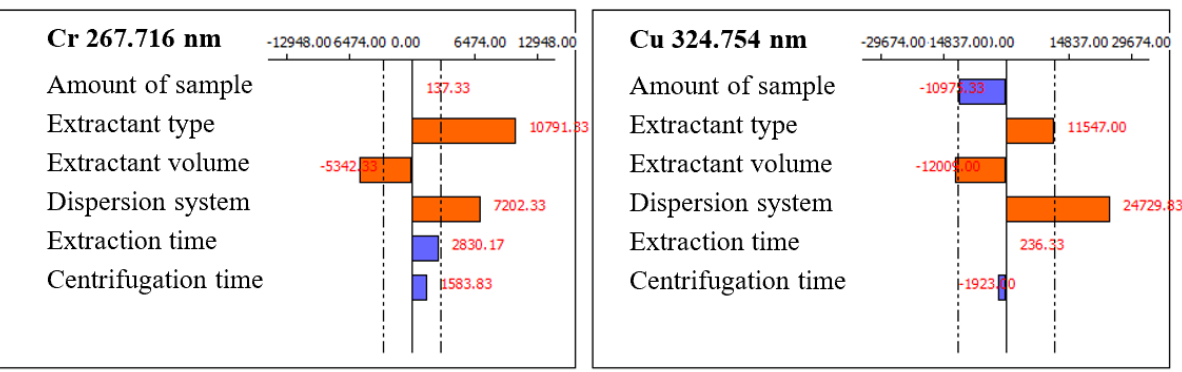

\begin{tabular}{|c|c|c|c|}
\hline Hg $253.652 \mathrm{~nm}$ & $7928.00-3964.000 .00$ & 3964.00 & 7928.00 \\
\hline Amount of sample & $-11 p^{\dot{\alpha}} 7$ & & \\
\hline Extractant type & & & 6607.9 \\
\hline Extractant volume & $-3669 \sqrt{2}$ & & \\
\hline Dispersion system & & & 5772.75 \\
\hline Extraction time & & 1372.58 & \\
\hline Centrifugation time & -18.5 & & \\
\hline & $\vdots$ & & \\
\hline
\end{tabular}

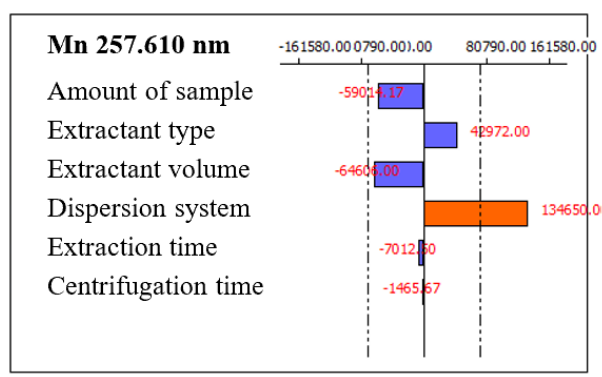

\section{Mo $202.032 \mathrm{~nm}$}

Amount of sample Extractant type Extractant volume Dispersion system Extraction time Centrifugation time
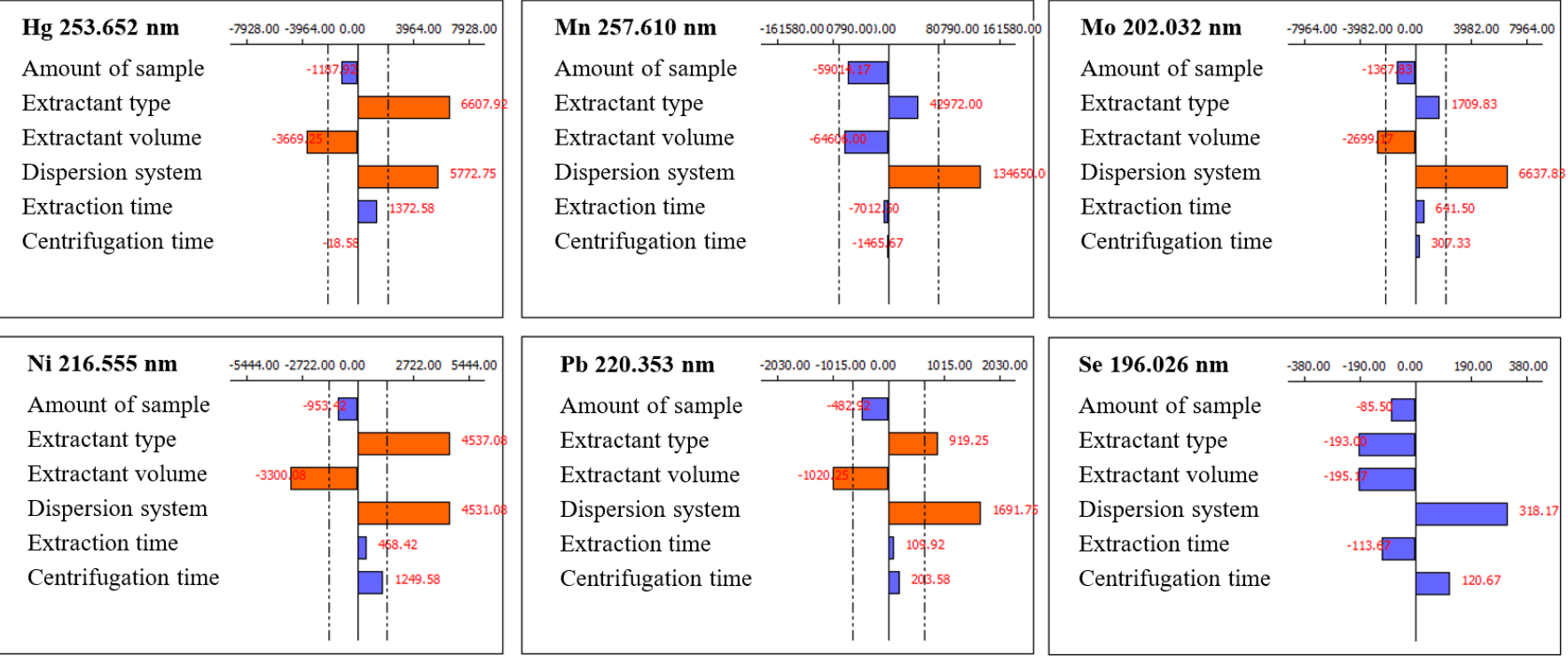

\begin{tabular}{|c|c|c|}
\hline S $181.972 \mathrm{~nm}$ & $-8774.00-4387.000 .00$ & $4387.00 \quad 8774.00$ \\
\hline Amount of sample & -959. . & \\
\hline Extractant type & & 5200.67 \\
\hline Extractant volume & -4264 & \\
\hline Dispersion system & & 7313.1 \\
\hline Extraction time & & $\mid \$ \$ \$ 13.33$ \\
\hline Centrifugation time & & 333.00 \\
\hline & $\vdots$ & $\vdots$ \\
\hline
\end{tabular}

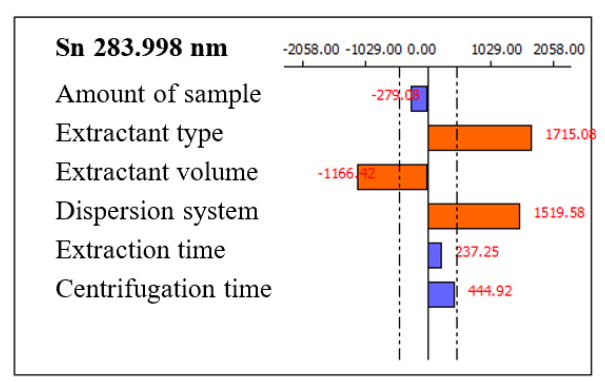

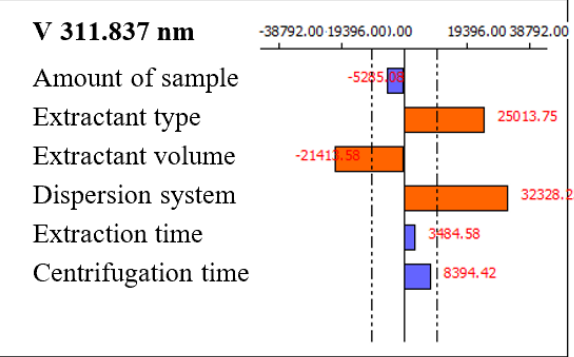

Figure 2. Pareto charts obtained in the screening study of the experimental factors affecting the RP-DLLME for all the evaluated emission lines. 


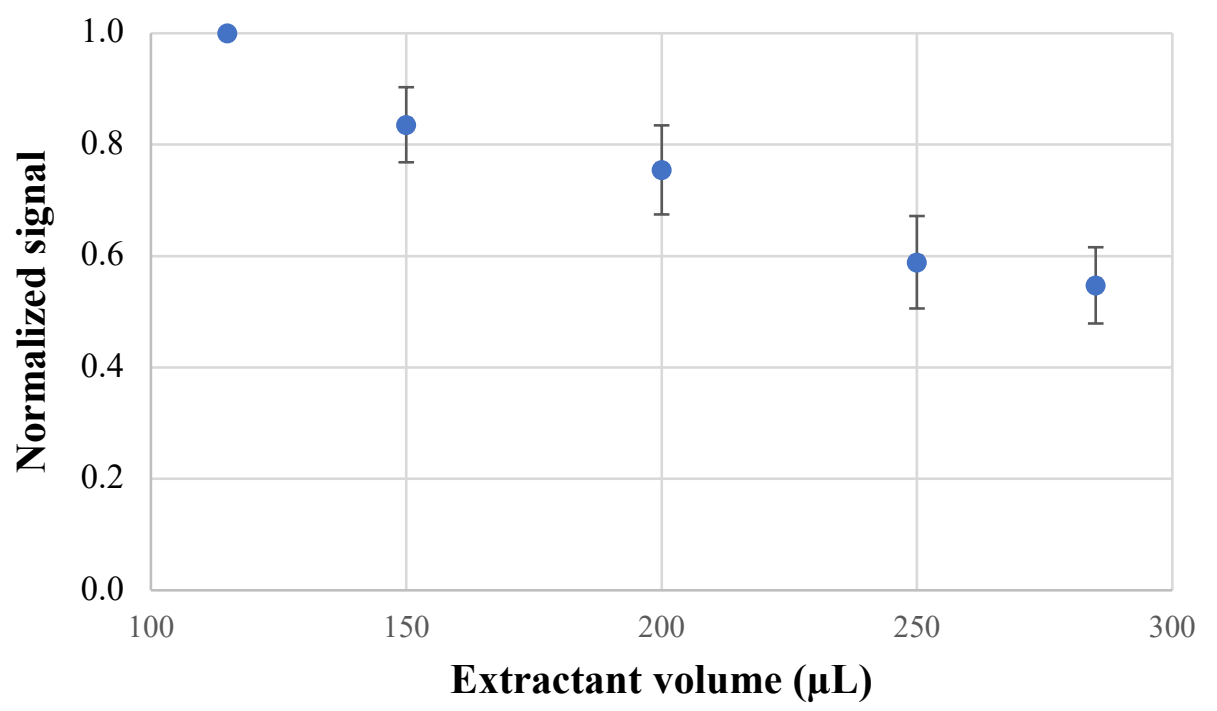

Figure 3. Effect of the extractant volume in RP-DLLME. Error bars represent the standard deviation of all emission lines evaluated. The experimental conditions for the microextraction procedure were: $5 \mathrm{~g}$ of amount of sample, $\mathrm{HCl} 8 \mathrm{M}$ as extractant phase, vortex as dispersion system, and 2 min for extraction and 5 min centrifugation time. 


\section{References}

1. Aguirre, M.A.; Canals, A.; López-García, I.; Hernández-Córdoba, M. Determination of cadmium in used engine oil, gasoline and diesel by electrothermal atomic absorption spectrometry using magnetic ionic liquidbased dispersive liquid-liquid microextraction. Talanta 2020, 220, 121395.

2. Duyck, C.; Miekeley, N.; da Silveira, C.L.P.; Aucelio, R.Q.; Campos, R.C.; Grinberg, P.; Brandao, G.P. The determination of trace elements in crude oil and its heavy fractions by atomic spectrometry. Spectrochim. Acta B 2007, 62, 939951. DOI: https://doi.org/10.1016/j.sab.2007.04.013.

3. $\quad$ Lin, Y.C.; Li, Y.C.; Amesho, K.T.; Shangdiar, S.; Chou, F.C.; Cheng, P.C. Chemical characterization of $\mathrm{PM}_{2.5}$ emissions and atmospheric metallic element concentrations in $\mathrm{PM}_{2.5}$ emitted from mobile source gasoline-fueled vehicles. Sci. Total Environ. 2020, 739, 139942.

4. Meira, L.A.; Almeida, J.S.; Dias, F.S.; Pedra, P.P.; Pereira, A.L.C.; Teixeira, L.S.G. Multi-element determination of $\mathrm{Cd}, \mathrm{Pb}, \mathrm{Cu}, \mathrm{V}, \mathrm{Cr}$, and $\mathrm{Mn}$ in ethanol fuel samples using energy dispersive $\mathrm{X}$-ray fluorescence spectrometry after magnetic solid phase microextraction using $\mathrm{CoFe}_{2} \mathrm{O}_{4}$ nanoparticles. Microchem. J. 2018, 142, 144-151.

5. $\quad$ Ferreira, V.J.; Almeida, J.S.; Lemos, V.A.; de Oliveira, O.M.C.; Garcia, K.S.; Teixeira, L.S.G. Determination of $\mathrm{Cu}, \mathrm{Ni}, \mathrm{Mn}$, and $\mathrm{Pb}$ in diesel oil samples using reversed-phase vortex-assisted liquid-liquid microextraction associated with energy dispersive X-ray fluorescence spectrometry. Talanta 2021, 222, 121514.

6. $\quad$ Lima, L.C.; Paixão, T.R.L.C.; Nomura, C.S.; Gaubeur, I. Combination of dispersive liquid-liquid microextraction and emulsion breaking for the determination of $\mathrm{Cu}$ (II) and $\mathrm{Pb}(\mathrm{II})$ in biodiesel and oil samples. Energy Fuels 2017, 31, 9491-9497.

7. Vicentino, P.O.; Cassella, R.J.; Leite, D.; Resano, M. Extraction induced by microemulsion breaking as a novel tool for the simultaneous determination of $\mathrm{Cd}, \mathrm{Mn}, \mathrm{Pb}$ and $\mathrm{Sb}$ in gasoline samples by ICP-MS and discrete sample introduction. Talanta 2020, 206, 120230.

8. Nomngongo, P.N.; Ngila, J.C. Determination of trace $\mathrm{Cd}, \mathrm{Cu}, \mathrm{Fe}, \mathrm{Pb}$ and $\mathrm{Zn}$ in diesel and gasoline by inductively coupled plasma mass spectrometry after sample clean up with hollow fiber solid phase microextraction system. Spectrochim. Acta B 2014, 98, 54-59.

9. Leite, C.C.; de Jesus, A.; Kolling, L.; Ferrão, M.F.; Samios, D.; Silva, M.M. Extraction method based on emulsion breaking for the determination of $\mathrm{Cu}, \mathrm{Fe}$ and $\mathrm{Pb}$ in Brazilian automotive gasoline samples by high-resolution continuum source flame atomic absorption spectrometry. . Spectrochim. Acta B 2018, 142, 62-67.

10. Nomngongo, P.N.; Ngila, J.C.; Msagati, T.A.; Moodley, B. Chemometric optimization of hollow fiber-liquid phase microextraction for preconcentration of trace elements in diesel and gasoline prior to their ICP-OES determination. Microchem. J. 2014, 114, 141-147.

11. Kobylinska, N.; Kostenko, L.; Khainakov, S.; Garcia-Granda, S. Advanced coreshell EDTA-functionalized magnetite nanoparticles for rapid and efficient magnetic solid phase extraction of heavy metals from water samples prior to the multi-element determination by ICP-OES. Microchim. Acta 2020, 187, 1-15. 
12. Sajid, M.; Alhooshani, K. Dispersive liquid-liquid microextraction based binary extraction techniques prior to chromatographic analysis: A review. Trend in Anal. Chem. 2018, 108, 167-182.

13. Aguirre, M.A.; Baile, P.; Vidal, L.; Canals, A. Metal applications of liquidphase microextraction. Trend in Anal. Chem. 2019, 112, 241-247.

14. Wang, Q.; Chen, R.; Shatner, W.; Cao, Y.; Bai, Y. State-of-the-art on the technique of dispersive liquid-liquid microextraction. Ultrason. sonochem. 2019, 51, 369-377.

15. Hashemi, P.; Raeisi, F.; Ghiasvand, A.R.; Rahimi, A. Reversed-phase dispersive liquid-liquid microextraction with central composite design optimization for preconcentration and HPLC determination of oleuropein. Talanta 2010, 80, 1926-1931.

16. Fernández, E.; Vidal, L.; Canals, A. Rapid determination of hydrophilic phenols in olive oil by vortex-assisted reversed-phase dispersive liquid-liquid microextraction and screen-printed carbon electrodes. Talanta 2018, 181, 44-51.

17. Kalschne, D.L.; Canan, C.; Barin, J.S.; Picoloto, R.S.; Leite, O.D.; Flores, E.L.M. Reversed-phase dispersive liquid-liquid microextraction (RP-DLLME) as a green sample preparation method for multielement determination in fish oil by ICP-OES. Food Anal. Method 2020, 13, 230-237.

18. Özzeybek, G.; Şahin, İ.; Erarpat, S.; Bakirdere, S. Reverse phase dispersive liquid-liquid microextraction coupled to slotted quartz tube flame atomic absorption spectrometry as a new analytical strategy for trace determination of cadmium in fish and olive oil samples. . J. Food Compos. Anal. 2020, 90, 103486.

19. Montgomery, D. Design and Analysis of Experiments. 7th ed.; Wiley: New Jersey, 2009.

20. Vicentino, P.O.; Cassella, R.J. Novel extraction induced by microemulsion breaking: a model study for $\mathrm{Hg}$ extraction from Brazilian gasoline. Talanta 2017, 162, 249-255.

21. Saha, B.; Sengupta, S. Extraction of thiophenic sulfur compounds from model fuel using a water-based solvent. Energ. Fuel 2017, 31, 996-1004.

22. Wu, Y.; Chen, M.; Wang, X.; Zhou, Y.; Xu, M.; Zhang, Z. Development and validation of vortex-assisted dispersive liquid-liquid microextraction method based on solidification of floating hydrophobic deep eutectic solvent for the determination of endocrine disrupting chemicals in sewage. Microchem. J. 2020, 163, 105915.

23. Psillakis, E. Vortex-assisted liquid-liquid microextraction revisited. Trend in Anal. Chem. 2019, 113, 332-339.

24. Magnusson, B.; Örnemark, U. Eurachem Guide: The Fitness for Purpose of Analytical Methods - A Laboratory Guide to Method Validation and Related Topics. 2 ed.; 2014. 